\title{
Hydration Characteristics of Selected Varieties of Paddy Rice from Nigeria
}

\author{
C. Ejebe, E. M. Kwofie, M. Ngadi ${ }^{*}$ \\ Department of Bioresource Engineering, McGill University, Québec, Canada \\ Email: *michael.ngadi@mcgill.ca
}

How to cite this paper: Ejebe, C., Kwofie, E.M. and Ngadi, M. (2019) Hydration Characteristics of Selected Varieties of Paddy Rice from Nigeria. Advances in Chemical Engineering and Science, 9, 65-75. https://doi.org/10.4236/aces.2019.91005

Received: September 26, 2018

Accepted: January 7, 2018

Published: January 10, 2018

Copyright ( 2019 by author(s) and Scientific Research Publishing Inc. This work is licensed under the Creative Commons Attribution International License (CC BY 4.0).

http://creativecommons.org/licenses/by/4.0/

(c) (i) Open Access

\begin{abstract}
In this study, water absorption characteristics of some rice varieties (Bisalayi, FARO 61, FARO 60, FARO 52 and FARO 44) from Nigeria were studied at $30^{\circ} \mathrm{C}, 45^{\circ} \mathrm{C}, 60^{\circ} \mathrm{C}$ and $75^{\circ} \mathrm{C}$ by determining the increase in grain weight as a function of time during soaking. Differences in moisture content among the selected varieties of paddy during soaking were significant $(\mathrm{P}<0.05)$ at all temperatures considered. Using the experimental moisture data, a non-linear regression procedure was applied to an analytical solution of the Fick's second law of the diffusion for an infinite cylinder. The predicted values of instantaneous moisture contents were in good agreement with the experiential data with $\mathrm{R}^{2}$ of $(0.834$ - 0.997). Water absorption rate was found to increase with soaking temperature, while water saturation time decreased with temperature. Average values of diffusion coefficients of moisture during soaking of paddy rice at different temperatures $\left(30^{\circ} \mathrm{C}, 45^{\circ} \mathrm{C}, 60^{\circ} \mathrm{C}\right.$ and $\left.75^{\circ} \mathrm{C}\right)$ were estimated as $6.25 \times 10^{-11}, 6.28 \times 10^{-11}, 7.02 \times 10^{-11}$, and $5.51 \times 10^{-11}$ and $5.52 \times 10^{-11} \mathrm{~m}^{2} / \mathrm{s}$ for Bisalayi, FARO 61, FARO 60, FARO 52 and FARO 44, respectively. The activation energies of the diffusivity through different varieties of rice grains were calculated using Arrhenius-type equation for diffusion dependence on temperature and were determined as 41.96, 38.69, 40.16, 34.05 and $42.12 \mathrm{~kJ} / \mathrm{mole}$ for Bisalayi, FARO 61, FARO 60, FARO 52 and FARO 44 for the respectively rice variety above.
\end{abstract}

\section{Keywords}

Rice Paddy, Parboiling, Hydration Rates, Saturation Time, Diffusion Coefficient, Activation Energy

\section{Introduction}

Parboiling is a pre-milling hydrothermal (heating and hydration) handling of paddy (rough rice) which brings about substantial physical and chemical altera- 
tions in rice. The main purpose of this process is to gelatinize the starch granules, transforming the ordered structure of the starch into a disordered one. Starch gelatinization imparts additional hardness to the rice grains and makes them to withstand harsher milling [1] [2]. Research shows that parboiled rice also has better organoleptic properties, retains more nutrients and cooks better than non-parboiled rice [1].

Paddy parboiling process is made up of three stages: soaking of paddy to saturation moisture content (SMC), steam heat treatment of the soaked paddy to gelatinize the rice starch and drying the steamed product to moisture content adequate for milling. Soaking is an essential operation done to achieve fast and uniform distribution of moisture in grains required for efficient gelatinization of starch granules during steaming operation, but it is time-consuming. Complete soaking is attained when there is an optimal absorption of water in the center of the soaked grains and when no white belly is observed in kernels of parboiled paddy. The moisture content corresponding to this condition is the SMC and has been found to be approximately $30 \%$ (w.b.) [3] [4] [5]. At this moisture content, steaming operation produced more translucent grains [6]. Bhattacharya and Rao [3] reported that insufficient soaking causes breakage of paddy during milling. Over-soaking (SMC > 31\%) due to excess water absorption induces husk splitting and leaching of paddy constituents [7].

Traditionally, soaking of paddy is done by steeping the product in water at ambient temperature, and allowing it to stay for $2-3$ days before draining the water. Increasing the temperature of soaking water, generally to that of starch gelatinization, reduces the time required for paddy to reach saturation [3].

Since soaking is an essential operation, understanding the characteristics of water movement during the process is of practical importance. More so it affects quality of the final product. However, each variety paddy has a unique optimal soaking time at different temperatures, that is, the time required to reach saturation. Hydration characteristics of different varieties of paddy have been studied. Bhattacharya and Rao [3] reported that freshly harvested paddy has lower hydration rate than stored grains. Hydration rate during soaking of high amylose rough rice varieties from Bangladesh was found to differ owing to difference in gelatinization temperatures [8]. It is not only essential to understand how fast water absorption takes place, but also to know how one can predict the soaking time at different water temperatures.

In a study by [8], it was reported that by soaking rough rices varying in gelatinization temperatures for $8 \mathrm{~h}$ at $60^{\circ} \mathrm{C}$, differences in rate of water absorption can be reduced. Differential scanning calorimeter (DSC) has been employed to measure gelatinization properties of rice [9] [10] [11]. The authors reported a range of gelatinization temperatures of $60^{\circ} \mathrm{C}-94^{\circ} \mathrm{C}$.

There are published data on hydration characteristics of South American and Asian rice grains in the literature [12] [13]. However, quantitative studies on water absorption characteristics of paddy varieties from West Africa, especially 
Nigeria need related studies and appear very scanty in the literature [14]. The objectives of this study were to:

1) Study hydration characteristics of different varieties of rice paddy (namely Bisalayi, FARO 61, FARO 60, FARO 52 and FARO 44) from Nigeria at $30^{\circ} \mathrm{C}$, $45^{\circ} \mathrm{C}, 60^{\circ} \mathrm{C}$ and $75^{\circ} \mathrm{C}$ soaking temperatures.

2) Determine moisture diffusivity and activation energy during hydration of the rice paddies.

\section{Materials and Methods}

\subsection{Material Sourcing}

Samples of, four improved rice varieties (FARO 44, FARO 52, FARO 60, FARO 61) used in this study were harvested in December, 2012 and collected from the Breeding Unit of Rice Research Program, National Cereal Research Institute (NCRI) Badeggi Niger State, Nigeria. One local variety (Bisalayi) was also harvested in the same period and obtained from crop improvement unit of Kano State Agriculture and Rural Development Agency (KNARDA). They were packed in nylon jute bags and transported to the Bioresource Engineering Department, McGill University, Montreal, Canada and stored at room temperature. Prior to experiments, the unparboiled paddy samples were taken out, thoroughly cleaned and extraneous materials and flawed grains were removed. The moisture contents of the samples were determined by the fixed air-oven method drying at $120^{\circ} \mathrm{C}$ for $24 \mathrm{~h}$ in duplicates and found to be $0.0713 \pm 0.0023 \mathrm{~g} / \mathrm{g}$ d.b.

\subsection{Determination of the Physical Characteristics of Paddy}

Physical characteristics of the paddy varieties were determined according to Varnamkhasti et al. [15] with slight modifications. For each rice variety, 50 grains were selected at random and their principle dimensions length $(L)$, breadth (B), and thickness $\left(T_{G}\right)$ measured using a digital vernier caliper to the accuracy of $0.01 \mathrm{~mm}$. Using the different values, the equivalent diameter $\left(D_{p}\right)$ in $\mathrm{mm}$ considering a prolate spheroid shape for a paddy grain was calculated according to [16].

$$
D_{p}=\left(L \frac{\left(B+T_{G}\right)^{2}}{4}\right)^{\frac{1}{3}}
$$

where $D_{p}$ is the equivalent diameter, $L$, the grain length, $B$, the breath of the grain and $T_{G}$ the grain thickness

\subsection{Soaking Procedure}

Samples of Paddy $(\approx 10 \mathrm{~g})$ in duplicates were placed in wire mesh and soaked in a $500 \mathrm{ml}$ beaker containing $400 \mathrm{ml}$ of distilled water. Before the run, the beaker was placed in a stirred water bath (T 1404 B Lauda, Lauda Dr. R. Wobser GMBH \& Co., Germany) which was set to the desired temperature for the experiment. The temperature of the waterbath was controlled at $\left( \pm 0.2^{\circ} \mathrm{C}\right)$ and the soaking 
temperatures were $30^{\circ} \mathrm{C}, 45^{\circ} \mathrm{C}, 60^{\circ} \mathrm{C}$, and $75^{\circ} \mathrm{C}$. Samples were drawn at different intervals $(1,2,3,4,5,6,7,8$ and $9 \mathrm{~h})$ and the soaked samples (without net) was surface-dried with paper towel to remove adhering surface water. The blotting procedure was repeated twice after which samples were reweighed in a balance with $0.0001 \mathrm{~g}$ accuracy to determine the increase in sample mass. Moisture content was rechecked by drying soaked sample a fixed air-oven at $105^{\circ} \mathrm{C}$ for $24 \mathrm{~h}$.

\subsection{Determination of Effective Diffusivity and Activation Energy}

The hydration kinetics of paddy rices was analyzed according to Fick's second law of diffusion. To simulate this, the following assumptions were made:

1) The effective diffusivity is independent of moisture content;

2) The volume of grain remains constant during water absorption;

3) The surface of the grain reaches saturation instantaneously upon immersion in water.

The analytical solution to the diffusion equation is an infinite series [17] and was applied to model hydration process during soaking of paddy rice.

$$
M R=\frac{M_{t}-M_{e}}{M_{o}-M_{e}}=\sum_{n=1}^{\infty} B_{i} \exp \left(-D_{e f f} \lambda_{i}^{2} t\right)
$$

where $M R$ is the moisture ratio, $M_{o}$ is the initial moisture content, $M(t)$ is the instantaneous moisture content $M_{e}$ is the equilibrium moisture content, $B_{i}$ is constant depending on the shape of the product, $D_{\text {eff }}$ is the diffusivity $\left(\mathrm{m}^{2} / \mathrm{s}\right)$ and $\lambda$ is the geometrical shape factor. As time gets larger, the infinite series on the right hand side of Equation (2) converges such that the momentary moisture content can be expressed as:

$$
\begin{gathered}
M(t)=M_{e}+\left(M_{o}-M_{e}\right) B_{i} \exp (-k t) \\
\text { where; } k=D_{e f f} \lambda_{i}^{2}
\end{gathered}
$$

To determine the equilibrium moisture content another set of samples were soaked for $30 \mathrm{~h}$ at $30^{\circ} \mathrm{C}, 24 \mathrm{~h}$ at $45^{\circ} \mathrm{C}, 15 \mathrm{~h}$ at $60^{\circ} \mathrm{C}$ and $10 \mathrm{~h}$ at $75^{\circ} \mathrm{C}$. These conditions were selected due to the fact that prolonged soaking in water temperature at $30^{\circ} \mathrm{C}$ may result in germination of rice kernels [18]. Shorter soaking periods were chosen for higher temperatures since absorption rate were faster at higher temperatures than at lower temperature. The equilibrium moisture content was also estimated by regression analysis of the experimental data using Equation (3).

Geometrically, rice grain could be considered as a cylinder, the infinite series solution infinite cylinder was evaluated to determine the model that best describes water absorption characteristics of rice.

The correct model could be estimated from the empirical values of $B_{1}$ and this was evaluated by applying a non-linear regression procedure (PROC MODEL) using SAS 9.2 to Equation (3) (known as the Henderson and Pabis diffusion equation). The optimum soaking time was taken as the minimum time required 
reaching the saturation moisture content.

Temperature dependence of diffusion coefficient is generally described using Arrhenius-type relationship to obtain an agreement of the predicted value with experimental data:

$$
D_{\text {eff }}=D_{0} \exp \left(-\frac{E_{a}}{R T}\right)
$$

where $D_{0}$ is the pre-exponential factor $\left(\mathrm{m}^{2} / \mathrm{s}\right), E_{a}$ is the activation energy (kJ/mole), $R$ is the gas constant $(8.314 \mathrm{~J} / \mathrm{mole} / \mathrm{K})$ and $T$ is the absolute temperature.

\section{Results and Discussion}

\subsection{Water Absorption Curves of Paddy}

The relationship between moisture content of paddy rice and soaking period at different temperatures is shown in Figure 1 and Figure 2 for Bisalayi and FARO 52 varieties, respectively. The hydration characteristics for FARO 61 follow similar pattern as Figure 1, while those of FARO 60 and FARO 44 follow similar pattern as and Figure 2.

During soaking up at $60^{\circ} \mathrm{C}\left(30^{\circ} \mathrm{C}, 45^{\circ} \mathrm{C}\right.$, and $\left.60^{\circ} \mathrm{C}\right)$, paddies absorbed water at a slow rate and reached equilibrium. This observation was consistent with finding by other authors during soaking of other rice [3] [12]. The saturation moisture content for rice in this study was found to be between $37.05 \%-42.70 \%$ dry basis. During soaking, FARO 44, 52 and 60 exhibited similar water absorption characteristics. However, a rapid deviation in the soaking characteristics from the normal trend was observed when soaking water temperature of at $75^{\circ} \mathrm{C}$ was used for FARO 44, 52 and 60. This could be as a result of volume expansion of

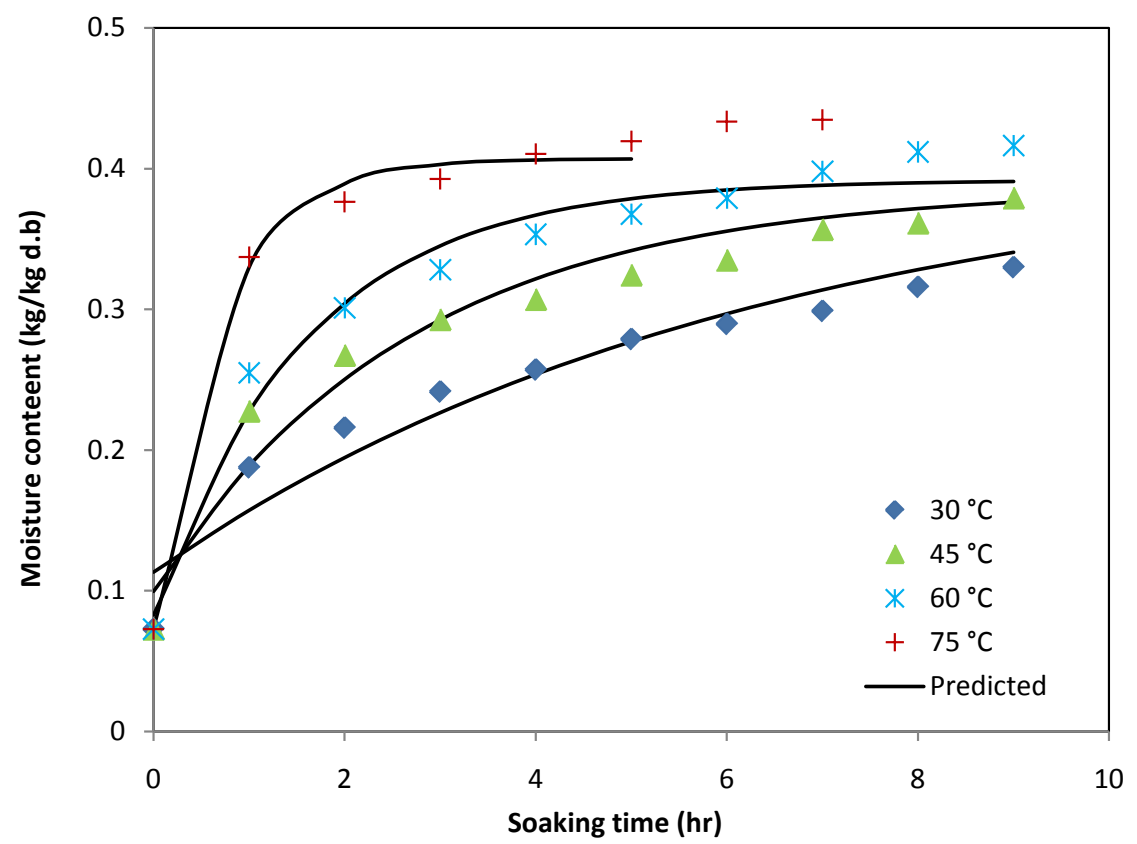

Figure 1. Moisture gain by Bisalayi rice variety at different soaking temperatures. 


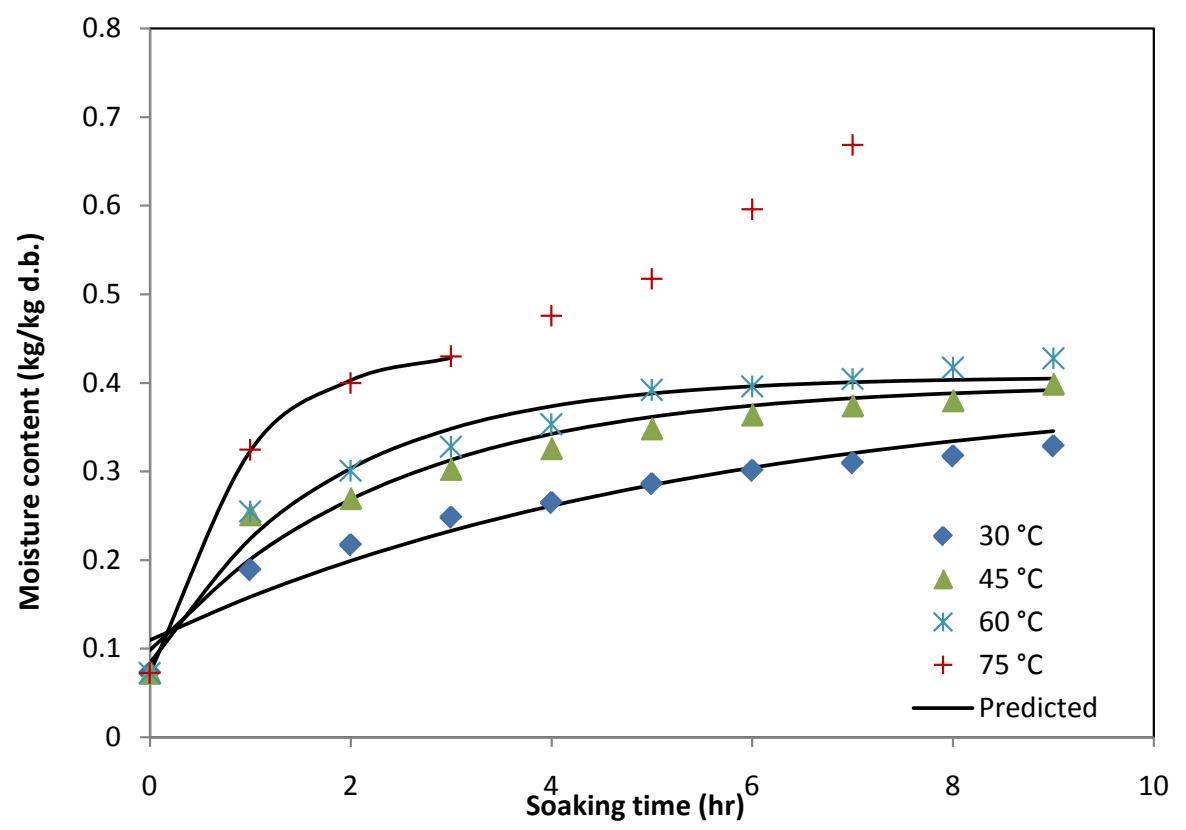

Figure 2. Moisture gain by FARO 52 rice variety at different soaking temperatures.

starches of FARO 44, 52 and 60 under the influence of high temperature. The increase in water uptake of FARO 44,52 and 60 continued without flattening out in the time range of the experiment. A further increase in water uptake was observed accompanied by husk splitting. This observation could be due to the fact that the starch gelatinization temperatures of FARO 44, 52 and 60 fall within the temperature range of $60^{\circ} \mathrm{C}$ to $75^{\circ} \mathrm{C}$. Igathinathane et al. [19] reported that as husks split, endosperms of paddies may react with water resulting in excess hydration or over-soaking of paddy. This observation was also made for rice used in this study. Husk splitting was observed after $3 \mathrm{~h}$ of soaking at $75^{\circ} \mathrm{C}$ water temperature for FARO 44, 52 and 60.

Furthermore, FARO 61 and Bisalayi were found to have similar water absorption characteristic curves. At $75^{\circ} \mathrm{C}$ soaking water temperature, husk splitting was observed after 5 hours of soaking for FARO 61 and Bisalayi. Bhattacharya et al. [7] reported that over-soaking due to prolonged steeping of paddy can lead to excessive migration of dissolved husk component to the endosperm thereby causing adverse colour change and result in poor quality of parboiled rice. Adverse colour change can also result from sever soaking at high temperature, leading to nonenzymatic browning as a result of chemical reaction of reducing sugar at high temperature. In other to optimize the soaking process, water temperature of $60^{\circ} \mathrm{C}$ was recommended since it does not result in husk splitting during soaking. At $60^{\circ} \mathrm{C}$ soaking water temperature, FARO 44, 52 and Bisalayi were found to reach saturation after $7 \mathrm{~h}$ of soaking, while FARO 60 and 61 attained saturation after 6 and $8 \mathrm{~h}$, respectively. Soaking periods, resulting in deviation from normal hydration characteristics before the splitting of husk were used in estimating the kinetic parameter for $75^{\circ} \mathrm{C}$. 


\subsection{Estimation of Kinetic Parameters}

In order to estimate moisture diffusivity during soaking of different varieties of paddy, a non-linear regression procedure was applied to Equation (3) as stated in the material and methods. The estimated values of parameters for different varieties of paddy are given in Table 1 . As expected, the value coefficient of water absorption $(k)$ increased with soaking temperature.

The characteristic lengths (radii) of the infinite cylinder model were calculated assuming that the model cylinder has the same volume and length as the rice kernel. The average values of radii for the infinite cylinder were $0.86,0.87,0.87$, 0.83 and $0.84 \mathrm{~mm}$ for Bisalayi, FARO 61, FARO 60, FARO 52 and FARO 44, respectively. The average value of $B_{1}$ for all varieties was observed to be $0.944 \pm$ 0.0064 which is close to the theoretical value for diffusion model in infinite cylinder (0.69). Similar observation was made for other paddy rice and was reported to be $0.917 \pm 0.0495$ [13]. Thus, it can be concluded that the water absorption characteristics of paddy rice were similar to those of an infinite cylindrical model.

Table 1. Kinetic parameters of Equation (3) for different varieties of paddy during soaking at different temperatures.

\begin{tabular}{|c|c|c|c|c|c|}
\hline Varieties & Temperature & $B$ & $k$ & $\mathrm{R}^{2}$ & MSE \\
\hline \multirow[t]{4}{*}{ Bisalayi } & 30 & $0.881 \pm 0.001$ & $0.159 \pm 0.002$ & 0.950 & 0.0005 \\
\hline & 45 & $0.915 \pm 0.003$ & $0.373 \pm 0.011$ & 0.944 & 0.0006 \\
\hline & 60 & $0.969 \pm 0.013$ & $0.629 \pm 0.048$ & 0.976 & 0.0004 \\
\hline & 75 & $0.998 \pm 0.002$ & $1.464 \pm 0.065$ & 0.994 & 0.0002 \\
\hline \multirow[t]{4}{*}{ FARO 61} & 30 & $0.898 \pm 0.003$ & $0.149 \pm 0.001$ & 0.963 & 0.0004 \\
\hline & 45 & $0.920 \pm 0.009$ & $0.406 \pm 0.008$ & 0.938 & 0.0007 \\
\hline & 60 & $0.966 \pm 0.010$ & $0.583 \pm 0.022$ & 0.978 & 0.0003 \\
\hline & 75 & $0.995 \pm 0.002$ & $1.187 \pm 0.040$ & 0.992 & 0.0001 \\
\hline \multirow[t]{4}{*}{ FARO 60} & 30 & $0.907 \pm 0.0003$ & $0.165 \pm 0.005$ & 0.834 & 0.0003 \\
\hline & 45 & $0.936 \pm 0.011$ & $0.400 \pm 0.009$ & 0.931 & 0.0008 \\
\hline & 60 & $0.977 \pm 0.002$ & $0.655 \pm 0.033$ & 0.985 & 0.0003 \\
\hline & 75 & $0.999 \pm 0.0002$ & $1.379 \pm 0.114$ & 0.999 & 0.0000 \\
\hline \multirow[t]{4}{*}{ FARO 52} & 30 & $0.887 \pm 0.011$ & $0.183 \pm 0.006$ & 0.951 & 0.0005 \\
\hline & 45 & $0.921 \pm 0.002$ & $0.418 \pm 0.001$ & 0.948 & 0.0006 \\
\hline & 60 & $0.965 \pm 0.009$ & $0.569 \pm 0.044$ & 0.978 & 0.0004 \\
\hline & 75 & $0.999 \pm 0.001$ & $1.145 \pm 0.076$ & 0.999 & 0.00002 \\
\hline \multirow[t]{4}{*}{ FARO 44} & 30 & $0.890 \pm 0.004$ & $0.133 \pm 0.003$ & 0.952 & 0.0005 \\
\hline & 45 & $0.904 \pm 0.008$ & $0.316 \pm 0.002$ & 0.943 & 0.0007 \\
\hline & 60 & $0.962 \pm 0.002$ & $0.587 \pm 0.014$ & 0.972 & 0.0005 \\
\hline & 75 & $0.999 \pm 0.005$ & $1.186 \pm 0.089$ & 0.997 & 0.0002 \\
\hline
\end{tabular}

$k=$ coefficient of water absorption (Equation (4)); $B=$ shape dependent constant (Equation (3)); MSE = mean square error. 
The variation of effective diffusivity of paddy rice with temperature and the values of activation energies for different varieties of paddy rice are shown in Table 2. The values obtained for diffusivity for Bisalayi, FARO 61, FARO 60, FARO 52 and FARO 44 was statistically analyzed to understand varietal significance on water absorption of paddy.

The result of analysis of variance (ANOVA) at a $0.5 \%$ confidence level during soaking at water temperature of $30^{\circ} \mathrm{C}$ and $45^{\circ} \mathrm{C}$ shows no statistical difference in Bisalayi, FARO 61, FARO 60, and FARO 52 except for FARO 44. This observation suggests that the husk of FARO 44 provided more barriers to water penetration during soaking at $30^{\circ} \mathrm{C}$ and $45^{\circ} \mathrm{C}$ water temperatures than the husk of other varieties of paddy used in this study. During higher soak water temperatures $\left(60^{\circ} \mathrm{C}\right.$ and $\left.75^{\circ} \mathrm{C}\right)$, Bisalayi and FARO 60 were found to have the highest diffusivity

Table 2. Diffusion coefficient and activation energy of paddy rices.

\begin{tabular}{|c|c|c|c|c|c|}
\hline Variety & $D_{0}\left(\mathrm{~m}^{2} / \mathrm{s}\right)$ & Temperature $\left({ }^{\circ} \mathrm{C}\right)$ & $D_{\text {eff }}\left(\mathrm{m}^{2} / \mathrm{s}\right)$ & $E_{a}(\mathrm{~kJ} / \mathrm{mol})$ & $\mathrm{R}^{2}$ \\
\hline \multirow[t]{4}{*}{ Bisalayi } & $3.34 \mathrm{E}-4$ & 30 & $7.23 \mathrm{E}-12$ & 44.47 & 0.99 \\
\hline & & 45 & $1.76 \mathrm{E}-11$ & & \\
\hline & & 60 & $3.14 \mathrm{E}-11$ & & \\
\hline & & 75 & $7.54 \mathrm{E}-11$ & & \\
\hline \multirow[t]{4}{*}{ FARO 61} & $8.10 \mathrm{E}-5$ & 30 & $1.15 \mathrm{E}-12$ & 40.78 & 0.98 \\
\hline & & 45 & $8.64 \mathrm{E}-12$ & & \\
\hline & & 60 & $1.78 \mathrm{E}-11$ & & \\
\hline & & 75 & $7.37 \mathrm{E}-11$ & & \\
\hline \multirow[t]{4}{*}{ FARO 60} & $1.5 \mathrm{E}-4$ & 30 & $7.83 \mathrm{E}-12$ & 42.13 & 0.99 \\
\hline & & 45 & $1.96 \mathrm{E}-11$ & & \\
\hline & & 60 & $3.35 \mathrm{E}-11$ & & \\
\hline & & 75 & $7.22 \mathrm{E}-11$ & & \\
\hline \multirow[t]{4}{*}{ FARO 52} & $1.55 \mathrm{E}-5$ & 30 & $7.83 \mathrm{E}-12$ & 36.42 & 0.98 \\
\hline & & 45 & $1.86 \mathrm{E}-11$ & & \\
\hline & & 60 & $2.66 \mathrm{E}-11$ & & \\
\hline & & 75 & $5.53 \mathrm{E}-11$ & & \\
\hline \multirow[t]{4}{*}{ FARO 44} & $2.74 \mathrm{E}-4$ & 30 & $5.8 \mathrm{E}-12$ & 44.50 & 0.99 \\
\hline & & 45 & $1.4 \mathrm{E}-11$ & & \\
\hline & & 60 & $2.78 \mathrm{E}-11$ & & \\
\hline & & 75 & $5.83 \mathrm{E}-11$ & & \\
\hline
\end{tabular}

$D_{\mathrm{o}}=$ pre-exponential factor; $D_{\text {eff }}=$ effective moisture diffusivity coefficient; $E_{\mathrm{a}}=$ activation energy. 
$(\mathrm{P}<0.05)$, while FARO 44 and FARO 52 has the lowest diffusivity values. This could be that in addition to husk, the bran of FARO 44 and FARO 52 further retards water absorption during soaking. Kaptso et al. [20] reported a positive correlation between diffusivity and seed coats of different varieties of cowpea and groundnut, suggesting that seed coverings can play an important role during hydration of seeds. Bello et al. [12] and Thakur and Gupta [13] also reported that husk and bran layer declines the rate of water absorption during soaking of rice. The values obtained are in close agreement with those reported in the literature for other varieties of paddy [12] [13]. The plots of $\operatorname{Ln}\left(D_{\text {eff }}\right)$ against the reciprocal of absolute temperature show a linear relation and are presented in Figure 3 and Figure 4.

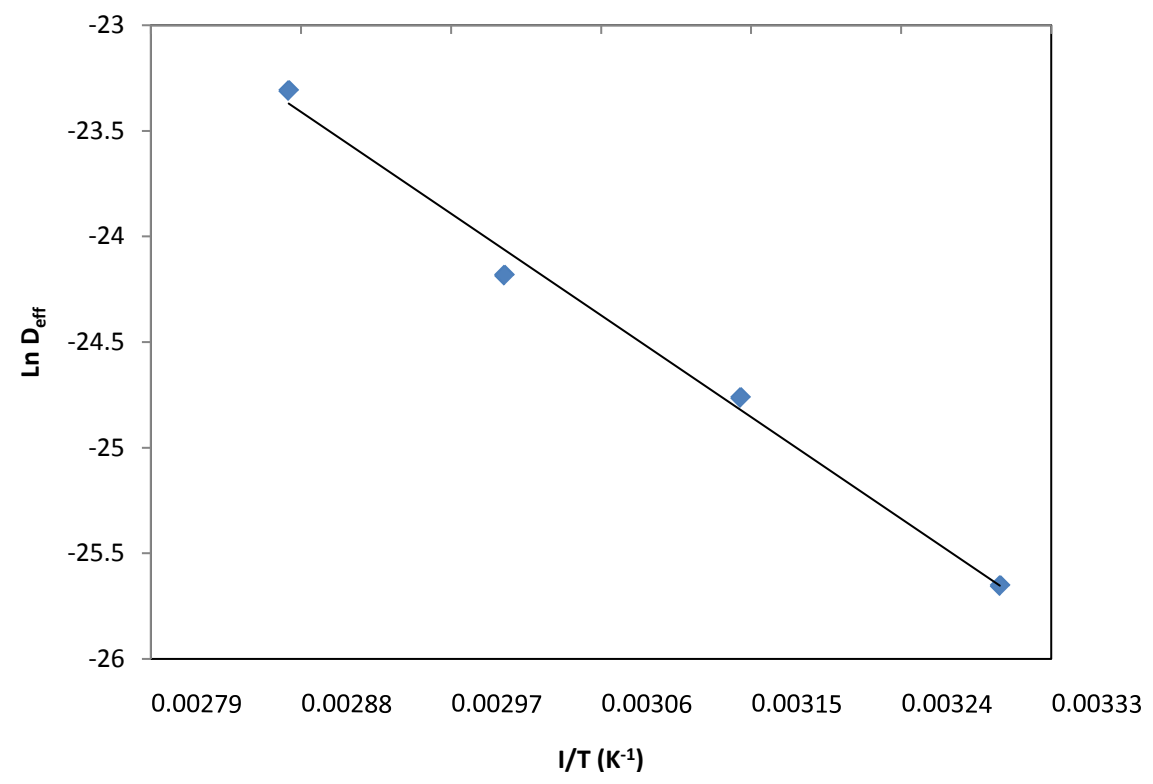

Figure 3. Arrhenius curve for the effect of soaking temperature on the effective diffusivity of Bisalayi paddy rice.

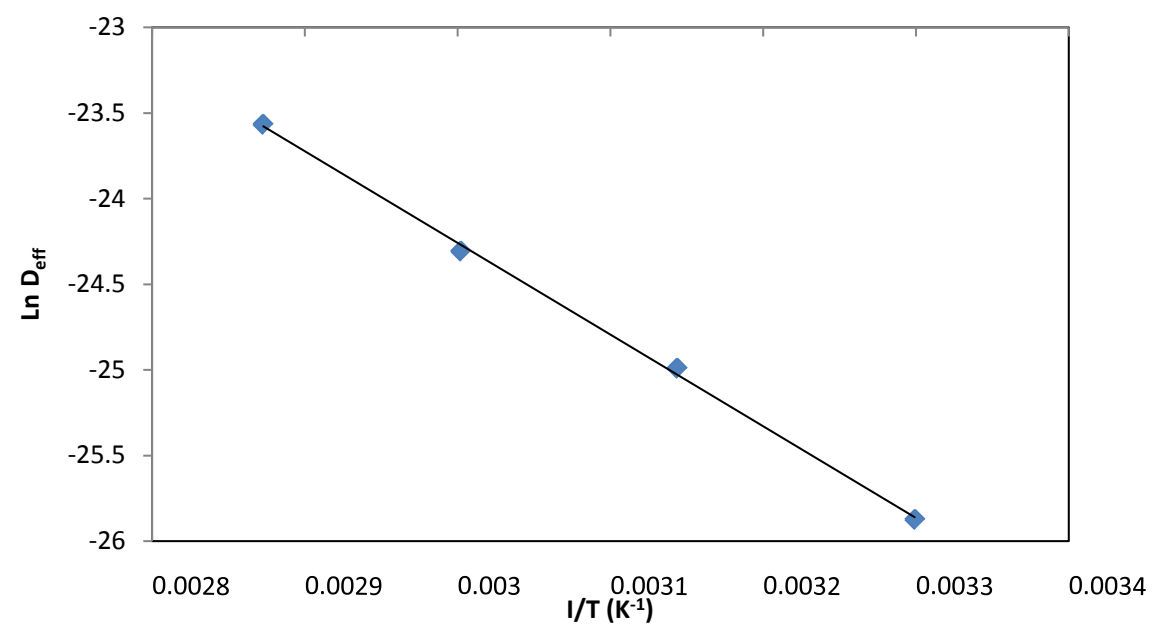

Figure 4. Arrhenius curve for the effect of soaking temperature on the effective diffusivity of FARO 44 paddy rice. 


\section{Conclusions}

Hydration characteristics of different varieties of paddy from West Africa (Nigeria) (FARO 61, FARO 60, FARO 52, FARO 44 and Bisalayi) were studied during soaking at low temperature $\left(30^{\circ} \mathrm{C}\right.$ and $\left.45^{\circ} \mathrm{C}\right)$ and high temperature $\left(60^{\circ} \mathrm{C}\right.$ and $75^{\circ} \mathrm{C}$ ) to suggest optimum soaking time for different varieties of paddy. Increase in temperature of soaking water increased the rate of water absorption and reduced the time for reaching saturation moisture content for paddy. However, during steeping at water temperature of $75^{\circ} \mathrm{C}, \mathrm{FARO} 44,52$ and 60 absorbed more water than Bisalayi and FARO 61, leading to husk splitting. Soaking in water temperature at $60^{\circ} \mathrm{C}$ did not result in excess water absorption nor husk splitting in paddy rice. Optimum soaking time (time to reach saturation moisture content) was observed to be $7 \mathrm{~h}$ for Bisalayi, FARO 44 and FARO 52, while for FARO 60 and FARO 61 the values were 6 and 8 h, respectively. The observed excess water absorbed during soaking of FARO 44, FARO 52 and FARO 60 could be attributed to the swelling and gelatinization of their starch.

A suitable prediction of water absorption during soaking of FARO 61, FARO 60, FARO 52, FARO 44 and Bisalayi was possible by fitting experimental data to Fick's diffusion equation with a high $\mathrm{R}^{2}$ value of $0.834-0.997$. The diffusivity of Bisalayi, FARO 61, FARO 60, FARO 52 and FARO 44 was $7.23 \times 10^{-12}-7.54 \times$ $10^{-11} \mathrm{~m}^{2} / \mathrm{s} ; 1.15 \times 10^{-12}-7.37 \times 10^{-11} \mathrm{~m}^{2} / \mathrm{s} ; 7.83 \times 10^{-12}-7.22 \times 10^{-11} \mathrm{~m}^{2} / \mathrm{s} ; 7.83 \times$ $10^{-12}-5.53 \times 10^{-11} \mathrm{~m}^{2} / \mathrm{s}$ and $5.80 \times 10^{-12}-5.83 \times 10^{-11} \mathrm{~m}^{2} / \mathrm{s}$, respectively with temperature range $30^{\circ} \mathrm{C}-75^{\circ} \mathrm{C}$.

An Arrhenius type equation described the strong dependence of diffusivity on temperature with activation values of $44.47,40.78,42.13,36.42$ and $44.50 \mathrm{~kJ} / \mathrm{mol}$ for Bisalayi, FARO 61, FARO 60, FARO 52 and FARO 44, respectively.

\section{Conflicts of Interest}

The authors declare no conflicts of interest regarding the publication of this paper.

\section{References}

[1] Rao, R.S.N. and Juliano, S.O. (1970) Effect of Parboling on Some Physico-Chemical Properties of Rice. Journal of Agricultural and Food Chemistry, 11, 289-294. https://doi.org/10.1021/jf60168a017

[2] Bhattacharya, K.R. (1985) Parboling of Rice. In: Rice: Chemistry and Technology, 289-348.

[3] Bhattacharya, K.R. and Subba Rao, P.V. (1966) Processing Conditions and Milling Yield in Parboiling of Rice. Journal of Agricultural and Food Chemistry, 14, 473-475. https://doi.org/10.1021/jf60147a008

[4] Gariboldi, F. (1974) Rice Parboiling. Paper No. 97, Food and Agricultural Organisation, Rome, 31-32.

[5] Wimberly, J.E. (1983) Parboiling. In: Technical Hand Book for the Paddy Rice Post Harvest Industry in Developing Countries, 101-116.

[6] Velupillai, L. and Verma, L.R. (1982) Parboiled Rice Quality as Affected by the Level and Distribution of Moisture after the Soaking Process. Transactions of the 
ASAE, 25, 1450-1456. https://doi.org/10.13031/2013.33745

[7] Bhattacharya, K.R. and Subba Rao, P.V. (1966) Effect of Processing Conditions on Quality of Parboiled Rice. Journal of Agricultural and Food Chemistry, 14, 476-479. https://doi.org/10.1021/jf60147a009

[8] Biswas, S.K. and Juliano, B.O. (1988) Laboratory Parboiling Procedures and Properties of Parboiled Rices from Varieties Differing in Starch Properties. Cereal Chemistry, 65, 417-423.

[9] Marshall, W.E., Wadsworth, J.I., Verma, L.R. and Velupillai, L. (1993) Determining the Degree of Gelatinization in Parboiled Rice: Comparison of Subjective and Objective Method. Cereal Chemistry, 70, 226-230.

[10] Saif, S.M.H., Lan, Y. and Sweat, V.E. (2003) Gelatinization Properties of Rice Flour. International Journal of Food Properties, 6, 531-542. https://doi.org/10.1081/JFP-120021457

[11] Ahmed, J., Ramaswamy, H.S., Ayad, A. and Alli, I. (2008) Thermal and Dynamic Rheology of Insoluble Starch from Basmatic Rice. Food Hydrocolloids, 22, 278-287. https://doi.org/10.1016/j.foodhyd.2006.11.014

[12] Bello, M., Tolaba, M.P. and Suarez, C. (2004) Factors Affecting Water Uptake of Rice Grain during Soaking. LWT-Food Science and Technology, 37, 811-816. https://doi.org/10.1016/j.lwt.2004.02.014

[13] Thakur, A.K. and Gupta, A.K. (2006) Water Absorption Characteristics of Paddy, Brown Rice and Husk during Soaking. Department of Processing and Food Engineering, Punjab Agricultural University, India.

[14] Shittu, T.A., Olaniyi, M.B., Oyekanmi, A.A. and Okeleye, K.A. (2012) Physical and Water Absorption Characteristics of Some Improved Rice Varieties. Food Bioprocess Technology, 5, 298-309. https://doi.org/10.1007/s11947-009-0288-6

[15] Varnamkhasti, M.G., Mobli, H., Jafari, A., Keyhani, A.R., Soltanabadi, M.H., Rafiee, S. and Kheiralipour, K. (2008) Some Physical Properties of Rough Rice (Oryza sativa L.) Grain. Journal of Cereal Science, 47, 496-501. https://doi.org/10.1016/j.jcs.2007.05.014

[16] Mohsenin, N.N. (1986) Physical Properties of Plant and Animal Materials. 2nd Edition, Gordon and Breach Science, New York, NY.

[17] Crank, J. (1975) The Mathematics of Diffusion. Oxford University Press, New York.

[18] Lu, R., Siebenmorgen, T.J. and Archer, T.R. (1994) Absorption of Water in Long-Grain Rough Rice during Soaking. Journal of Food Process Engineering, 17, 141-154. https://doi.org/10.1111/j.1745-4530.1994.tb00332.x

[19] Igathinathane, C., Chattopadhyay, P.K. and Pordesimo, L.O. (2005) Combination Soaking Procedure for Rough Rice Parboiling. Transactions of the ASAE, 48, 665-671. https://doi.org/10.13031/2013.18296

[20] Kaptso, K.G., Njintang, Y.N., Komnek, A.E., Hounhouigan, J., Scher, J. and Mbofung, C.M.F. (2008) Physical Properties and Rehydration Kinetics of Two Varieties of Cowpea (Vigna unguiculata) and Groundnuts (Voandzeia subterranea) Seeds. Journal of Food Engineering, 86, 91-99. https://doi.org/10.1016/j.jfoodeng.2007.09.014 